\title{
Pengaruh Social Media Marketing Activities Terhadap Attitudinal Loyalty dan Behavioural Loyalty pada Konsumen OVO
}

\author{
Mikhael Ming Khosasih, L. Verina Halim S. \\ University of Surabaya \\ e-mai:s134118007@student.ubaya.ac.id,verina@staff.ubaya.ac.id
}

\begin{abstract}
This day, social media has been developing. This media was used with company to close with consumer and gain more loyalty to brand. OVO Company has doing many activities in Instagram but the number of active customers not as much as their competitors. Go-Pay has the most active customer with social media activity not as much as OVO. This study aims to discuss the effect of social media marketing activities on OVO customer loyalty from attitudinal loyalty and behavioural loyalty with mediation customer satisfaction and perceived value. This study uses Structural Equation Model (SEM) and 150 respondents processed with SPSS 25 and AMOS 25. The result confirmed that there is positive relation but not significant between OVO customer satisfaction and behavioural loyalty.
\end{abstract}

Keywords: Social media marketing activities, perceived value, customer satisfaction, attitudinal loyalty, behavioural loyalty, e-wallet

\section{INTRODUCTION}

Internet telah berkembang di seluruh dunia. Saat ini penggunaan internet di dunia telah mencapai dua miliar pengguna (Belch dan Belch, 2018). Internet saat ini berdampak pada perkembangan media sosial untuk saling bertukar pesan (Kotler et al., 2018). Semakin majunya zaman internet telah membuat media sosial makin berkembang sehingga memiliki 3,2 miliar pengguna (Tjepkema, 2019). Media sosial tidak hanya digunakan untuk melakukan interaksi antarpengguna tetapi juga memiliki peranan penting sebagai kekuatan pemasaran (Macy dan Thompson, 2011). Media sosial merupakan alat pemasaran yang paling ampuh saat ini (Khan, 2019). Saat ini media sosial banyak digunakan oleh perusahaan atau sebuah merek untuk mendekatkan di kepada konsumen (Okazaki et al., 2015). Penggunaan media sosial ini sangat berguna untuk menumbuhkan relasi yang bersifat jangka panjang dengan para konsumen (Kotler et al.,
2018). Persaingan antar perusahaan saat ini menjadi sangat meningkat drastis akibat adanya media sosial (Lee et al., 2018). Setiap perusahaan berusaha untuk merebut hati para konsumen melalui media sosial.

Media sosial saat ini digunakan oleh banyak jenis perusahaan termasuk perusahaan dompet digital. Saat ini pertumbuhan dompet digital sangat berkembang pesat hingga 50\% pada kuartal ke-4 2017 (Devata, 2017). Terdapat 38 perusahaan dompet digital yang saling bersaing untuk merebut hati konsumen di Indonesia (Rizal, 2019). Hal ini menjadi tantangan bagi perusahaan untuk mampu menarik minat konsumen kemudian menjadi konsumen yang loyal agar dapat bertahan di industri dompet digital Indonesia. Tantangan lainnya adalah konsumen Indonesia adalah masyarakat berperilaku konsumtif tetapi memiliki penghasilan sedikit (Santoso dan Erdaka, 2019). Oleh karena itu, banyak konsumen yang tertarik menggunakan dompet 
digital karena adanya promo-promo pada perusahaan tersebut.

Aktivitas pemasaran melalui media sosial atau social media marketing activities dapat memengaruhi keberlanjutan konsumen untuk partisipasi dan melakukan pembelian (Chen dan Lin, 2019). Penelitian ini mengungkapkan bahwa social media marketing activities tidak berdampak langsung terhadap customer satisfaction. Padahal menurut Hanaysha (2017) aktivitas pemasaran melalui media sosial dapat meningkatkan kepuasan pelanggan. Interaksi melalui media sosial dan kualitas pelayanan yang baik dapat meningkatkan loyalitas dari konsumen (Lee et al., 2018). Pada penelitian ini mengungkapkan bahwa kepuasan pelanggan tidak memiliki pengaruh langsung terhadap behavioural loyalty. Hal ini tidak sejalan dengan penelitian dari Shahin dan Rahim (2014) kepuasan pelanggan berdampak pada attitudinal loyalty dan behavioural loyalty.

Dompet digital banyak menggunakan strategi media sosial untuk meningkatkan konsumen. Banyak masyarakat yang terpengaruh media sosial untuk menggunakan dompet digital (Mastercard, 2017). OVO dan Go-Pay adalah salah satu contoh dompet digital yang paling atas di Indonesia. Saat ini OVO memiliki jumlah pengikut dan aktivitas media sosial yang lebih tinggi dari Go-Pay. Tetapi jika dilihat dari pengguna aktifnya, OVO memiliki jumlah pengguna aktif yang lebih sedikit dibandingkan dengan Go-Pay. Hal ini tidak sejalan dengan teori Kotler yang mengungkapkan bahwa interaksi yang kuat dapat meningkatkan pemasaran jangka panjang hingga ke loyalitas konsumen. Penelitian ini akan membahas apakah ada hubungan antara penggunaan media sosial OVO terhadap loyalitas dari konsumen. Loyalitas ini pun juga dibagi menjadi dua yaitu attitudinal loyalty dan behavioural loyalty.
Penelitian ini juga menggunakan customer satisfaction dan perceived value sebagai mediasi antara social media marketing activities dengan loyalitas konsumen OVO. Penelitian ini juga menambahkan hubungan antara perceived value dengan attitudinal loyalty dan behavioural loyalty sesuai dengan penelitian Chua, Lee, dan Han (2017).

\section{CONCEPTUAL FRAMEWORK AND METH- ODOLOGY}

Menurut Belch dan Belch (2018), media sosial berguna untuk melakukan komunikasi atau interaksi antara pemasar dengan konsumen dan konsumen dengan konsumen. Contoh interaksi yang dilakukan oleh pemasar adalah layanan konsumen, mencari kebutuhan konsumen, hingga saling berbagi mengenai produk antar-konsumen. Menurut Hanaysha (2017), aktivitas tersebut dapat meningkatkan customer satisfaction. Konsumen juga akan puas ketika melakukan transaksi menggunakan aplikasi yang ada sehingga meningkatkan pengalaman yang dirasakan oleh konsumen (Verhagen et al., 2011). Pernyataan ini akan menjadi $\mathrm{H} 1$ dalam penelitian.

H1 Diduga ada pengaruh positif antara social media marketing activities (SMMVs) terhadap customer satisfaction.

Media sosial memungkinkan konsumen untuk mencari informasi, hiburan, dan remunerasi (Belch dan Belch, 2018). Saat mencari informasi, konsumen akan menangkap keunggulan dan berbagai informasi yang dimiliki oleh merek. Hal tersebut dimanfaatkan semaksimal mungkin oleh pemasar untuk memberikan berbagai nilainilai yang dimiliki perusahaan. Konsumen juga akan melakukan remunerasi yaitu nilai apa saja yang akan didapat dari penggunaan produk atau jasa tersebut. Hal tersebut membuat aktivitas 
melalui media sosial dapat berdampak positif pada perceived value. Pernyataan ini akan menjadi $\mathrm{H} 2$ dalam penelitian.

H2 Diduga ada pengaruh positif antara social media marketing activities (SMMVs) terhadap perceived value.

Menurut Chen (2019), konsumen yang puas akan memengaruhi orang tersebut untuk menjadi loyal terhadap suatu produk dan jasa. Bandyopadhyay dan Martell (2007) mengungkapkan bahwa loyalitas terbagi menjadi dua yaitu attitudinal dan behavioural loyalty. Attitudinal loyalty merupakan loyalitas yang dirasakan oleh konsumen yang merasa terikat dengan merek tertentu. Ketika konsumen puas akan memiliki perasaan ikatan yang kuat terhadap merek tertentu sehingga semakin customer satisfaction akan berdampak positif terhadap attitudinal loyalty. Pernyataan tersebut menjadi $\mathrm{H} 3$ dalam penelitian.

H3 Diduga ada pengaruh positif antara customer satisfaction terhadap attitudinal loyalty.

Menurut Chou (2015), masyarakat yang puas pada suatu pelayanan akan melakukan pembelian ulang untuk produk atau jasa yang sama di masa depan. Penelitian Tsai dan Huang (2007) juga mengatakan bahwa pelanggan yang puas menggunakan website tertentu untuk belanja online akan melakukan pembelanjaan ulang di kemudian hari. Konsumen tidak hanya akan menggunakan jasa atau membeli produk lagi tetapi akan merekomendasikan produk atau jasa tersebut kepada orang lain (Sano, 2019). Pernyataan tersebut menjadi $\mathrm{H} 4$ dalam penelitian.

H4 Diduga ada pengaruh positif antara customer satisfaction terhadap behavioural loyalty.

Penelitian sebelumnya telah mengungkapkan bahwa ada hubungan yang positif dan cukup kuat antara perceived value terhadap loyalitas (Llach et al., 2013). Jika sebuah merek mengalami penurunan pada perceived value yang mereka miliki maka konsumen akan cenderung untuk beralih menggunakan merek yang lebih unggul atau lebih baik lagi (El-Adly dan Eid, 2016). Oleh karena itu, perceived value yang meningkat akan berdampak baik terhadap loyalitas dari konsumen. Pernyataan tersebut menjadi $\mathrm{H} 5$ dalam penelitian.

H5 Diduga ada pengaruh positif antara perceived value terhadap attitudinal loyalty.

Penelitian dari Duman dan Mattila (2005) mengungkapkan bahwa adanya peningkatan nilai yang dimiliki perusahaan akan berdampak terhadap kemauan konsumen untuk melakukan pembelian atau mau menggunakan produk atau jasa tersebut. Kim dan Ok (2009) juga mengungkapkan bahwa ada hubungan yang sangat kuat antara nilai yang dimiliki oleh perusahaan terhadap komitmen konsumen untuk menggunakan ulang produk atau jasa tersebut sehingga ada pengaruh positif yang cukup kuat antara perceived value terhadap behavioural loyalty. Pernyataan tersebut menjadi H6 dalam penelitian.

H6 Diduga ada pengaruh positif antara perceived value terhadap behavioural loyalty.

Attitudinal loyalty merupakan loyalitas yang dirasakan oleh konsumen terikat dengan merek tertentu. Ketika konsumen puas akan memiliki perasaan ikatan yang kuat terhadap merek tertentu. Ikatan yang kuat tersebut akan membuat konsumen melakukan pembelian ulang terhadap suatu merek tertentu. Menurut Lee et al. (2018), behavioural loyalty merupakan tingkatan loyalitas yang lebih tinggi dari pada attitudinal loyalty. Pernyataan tersebut menjadi H6 dalam penelitian. 
H7 Diduga ada pengaruh positif antara attitudinal loyalty terhadap behavioural loyalty.

Jenis penelitian yang digunakan dalam penelitian ini adalah applied research karena dalam penelitian ini lebih fokus dalam membahas permasalahan yang dihadapi perusahaan OVO terkait media sosial (Sekaran dan Bougie, 2018). Penelitian ini juga tergolong causal research yaitu penelitian yang akan membahas hubungan sebab akibat (Sekaran dan Bougie, 2018). Hubungan antara social media marketing activities dengan loyalitas konsumen OVO dengan mediasi customer satisfaction dan perceived value. Penelitian ini juga tergolong penelitian kuantitatif karena menggunakan kuesioner untuk menjawab pertanyaan yang diajukan (Burns, Veeck, dan Bush, 2017). Data yang digunakan adalah data primer yang dihasilkan dari membagi kuesioner kepada konsumen OVO. Kuesioner akan berbentuk closeended dengan dua bagian yaitu bagian identitas dan pertanyaan. Kuesioner akan menggunakan aras interval dengan skala likert 1 hingga 5 .

Target populasi yang dipilih adalah semua konsumen OVO yang telah berusia minimal 17 tahun. Orang tersebut juga harus aktif di media sosial dan mengikuti Instagram OVO. Konsumen juga harus menggunakan OVO dalam tiga bulan terakhir. Kemudian populasi tersebut akan ditentukan dengan memilih sampel dengan menggunakan non-probability sampling dengan metode purposive sampling karena akan mengambil sampel sesuai dengan tujuan tertentu. Setelah data dikumpulkan kemudian akan diolah menggunakan uji validitas dan reliabilitas terhadap 30 data pertama menggunakan SPSS 25. Selanjutnya akan dihitung berdasarkan measurement model dengan uji validitas dan reliabilitas terhadap 150 data menggunakan AMOS 25. Perhitungan yang akan dilakukan adalah nilai construct reliability (CR) yang diterima jika memiliki nilai di atas 0,6 dan average variance extracted (AVE) yang akan diterima dengan nilai di atas 0,5. Perhitungan selanjutnya akan menghitung goodness of fit berdasarkan nilai CMIN/DF, RMSEA, GFI, CFI, dan TLI. Pada perhitungan terakhir akan melihat nilai structural model melalui perhitungan standard estimate, CRI, dan alpha.

\section{RESULT AND DISCUSSION}

Hasil penelitian menunjukkan bahwa hasil uji validitas dan reliabilitas tahap pertama dengan 30 kuesioner dan bantuan aplikasi SPSS 25 didapat nilai yang valid dan reliabel sehingga dilanjutkan pada perhitungan berikutnya menggunakan measurement model. Pada tahap penelitian ini sudah terkumpul sebanyak 150 data. Tahap berikutnya adalah menguji kecocokan dengan menggunakan CMIN/DF, RMSEA, GFI, CFI, dan TLI. Hasil pada uji kecocokan pada Tabel 1 menunjukkan bahwa nilai bisa diterima dan dilanjutkan pengolahan data selanjutnya. Kemudian diuji nilai standardized loading, AVE, dan CR. Hasil dari perhitungan dapat dilihat pada Tabel 2.

Tabel 1 Uji Kecocokan Measurement Model

\begin{tabular}{|c|l|c|c|c|}
\hline No. & $\begin{array}{c}\text { Uji } \\
\text { Kecocokan }\end{array}$ & $\begin{array}{c}\text { Kriteria } \\
\text { Kecocokan }\end{array}$ & Hasil & Keterangan \\
\hline 1 & CMIN/DF & $\leq 2$ & 1,634 & Good Fit \\
\hline 2 & RMSEA & $\leq 0,08$ & 0,065 & Good Fit \\
\hline 3 & GFI & $0,90-0,99$ & 0,872 & Marginal Fit \\
\hline 4 & CFI & $0,90-0,99$ & 0,939 & Good Fit \\
\hline 5 & TLI & $0,90-0,99$ & 0,925 & Good Fit \\
\hline
\end{tabular}

Tabel 1 menunjukkan nilai uji kecocokannya dapat diterima hanya bagian GFI terlihat mendapatkan peringkat marginal fit tetapi hal ini tidak menjadi masalah dan bisa dilanjutkan 
Tabel 2 Perhitungan Standardized Loading, AVE, and CR

\begin{tabular}{|c|c|c|c|c|c|c|}
\hline No. & Variabel & Indikator & $\begin{array}{c}\text { Std. } \\
\text { Loading }\end{array}$ & AVE & CR & Ket. \\
\hline \multirow{5}{*}{1} & \multirow{5}{*}{$\begin{array}{l}\text { Social } \\
\text { Media } \\
\text { Marketing } \\
\text { Activities }\end{array}$} & SMM1 & 0.815 & \multirow{5}{*}{0,548} & \multirow{5}{*}{0.858} & Valid \& Reliabe! \\
\hline & & S.MD2 & 0.636 & & & Valid \& Reliabel \\
\hline & & SMMB & 0,719 & & & Valid \& Reliabe! \\
\hline & & S.MM! & 0,771 & & & Valid \& Reliabe! \\
\hline & & SMM5 & 0,749 & & & Valid \& Reliabel \\
\hline \multirow{3}{*}{2} & \multirow{3}{*}{$\begin{array}{l}\text { Customer } \\
\text { Satisfaction }\end{array}$} & SAT1 & 0,854 & \multirow{3}{*}{0,534} & \multirow{3}{*}{0,771} & Valid \& Reliabel \\
\hline & & SAT2 & 0,629 & & & Valid \& Reliabe! \\
\hline & & SAT3 & 0.690 & & & Valid \& Reliabe! \\
\hline \multirow{4}{*}{3} & \multirow{4}{*}{$\begin{array}{l}\text { Perceived } \\
\text { Value }\end{array}$} & PVL1 & 0.718 & \multirow{4}{*}{0,495} & \multirow{4}{*}{0,796} & Valid \& Reliabel \\
\hline & & PVL2 & 0.695 & & & Valid \& Reliabe! \\
\hline & & PVL3 & 0,765 & & & Valid \& Reliabe! \\
\hline & & PVL4 & 0.630 & & & Valid \& Reliabe! \\
\hline \multirow{3}{*}{4} & \multirow{3}{*}{$\begin{array}{l}\text { Attitudinal } \\
\text { Loyalty }\end{array}$} & ATT1 & 0.696 & \multirow{3}{*}{0,599} & \multirow{3}{*}{0,816} & Valid \& Reliabel \\
\hline & & ATT2 & 0,745 & & & Valid \& Reliabe! \\
\hline & & ATT3 & 0.870 & & & Valid \& Reliabe! \\
\hline \multirow{3}{*}{5} & \multirow{3}{*}{$\begin{array}{l}\text { Behavioural } \\
\text { Loyalty }\end{array}$} & BVL1 & 0.695 & \multirow{3}{*}{0,601} & \multirow{3}{*}{0,818} & Valid \& Reliabe! \\
\hline & & BVL2 & 0,875 & & & Valid \& Reliabe! \\
\hline & & BVL3 & 0,745 & & & Valid \& Reliabe! \\
\hline
\end{tabular}

Std. Loading: Standardized Loading; Ket.:

Keterangan

untuk perhitungan berikutnya. Pada Tabel 2 juga ditunjukkan hasil perhitungan nilai dari standardized loading dapat diterima pada setiap indikator variabel social media marketing activities, customer satisfaction, perceived value, attitudinal loyalty, dan behavioural loyalty karena berhasil mendapatkan nilai $\geq 0,5$. Oleh karena itu, semua indikator dapat diterima, tetapi jika dilihat sekilas dari perhitungan tersebut adalah AVE dari variabel perceived value nilainya mendapatkan 0,495 yang seharusnya pada ketentuan harus mendapatkan nilai $\geq 0,5$. Hal ini tidak menjadi masalah karena pada percobaan standardized loading pada setiap variabel sudah mendapatkan nilai $\geq 0,05$ sehingga variabel perceived value dan indikatornya masih dapat dikatakan valid dan reliabel.

Dari perhitungan goodness of fit atau uji kecocokan dapat dilihat bahwa nilai dari uji CMIN/DF mendapatkan nilai 1,821 sehingga bisa disebut dengan good fit karena memiliki nilai kurang dari 2. Selanjutnya adalah uji RMSEA mendapatkan nilai yang sesuai yaitu 0,074 sehingga disebut dengan good fit. Nilai
CFI dan TLI juga mendapatkan keterangan good fit dengan nilai 0,919 dan 0,903 . Terakhir adalah GFI mendapatkan predikat marginal fit dengan nilai 0,857 tetapi masih tetap bisa diterima. Hasil perhitungan dari goodness of fit dapat dilihat pada Tabel 3 berikut.

Tabel 3 Uji Kecocokan Structural Model

\begin{tabular}{|c|l|c|c|c|}
\hline No. & $\begin{array}{c}\text { Uji } \\
\text { Kecocokan }\end{array}$ & $\begin{array}{c}\text { Kriteria } \\
\text { Kecocokan }\end{array}$ & Hasil & Keterangan \\
\hline 1 & CMIN/DF & $\leq 2$ & 1,821 & Good Fit \\
\hline 2 & RMSEA & $\leq 0,08$ & 0,074 & Good Fit \\
\hline 3 & GFI & $0,90-0,99$ & 0,857 & Marginal Fit \\
\hline 4 & CFI & $0,90-0,99$ & 0,919 & Good Fit \\
\hline 5 & TLI & $0,90-0,99$ & 0,903 & Good Fit \\
\hline
\end{tabular}

Tahap paling terakhir dalam pengolahan data adalah pengujian hipotesis. Tahap ini dapat dilakukan setelah menyelesaikan perhitungan dan pengujian pada measurement model dan structural model. Pengujian hipotesis dilakukan menggunakan aplikasi AMOS 25. Pengujian ini dilakukan untuk memastikan hubungan antara variabel sesuai dengan hipotesis yang pertama diajukan pada Bab 2. Pada pengujian hipotesis ini akan melihat dua bagian penting. Pertama adalah nilai dari standard estimate dan critical ratio atau p-value. Dalam perhitungan kali ini nilai alpha yang akan digunakan adalah sebesar 0,1. Nilai standard estimate akan diterima jika memiliki arah hubungan yang sesuai dengan hipotesis. Hipotesis akan diterima jika memiliki nilai CRI (critical ratio) lebih besar atau sama dengan 1,645. Jika nilai tidak sesuai dengan kriteria di atas maka hipotesis tidak dapat diterima.

Kesimpulan dari hasil pengujian hipotesis, semua hipotesis mulai dari $\mathrm{H} 1$ hingga $\mathrm{H} 3$ dan $\mathrm{H} 5$ hingga $\mathrm{H} 7$ diterima dalam penelitian ini. Hipotesis yang tidak dapat diterima adalah $\mathrm{H} 4$ karena memiliki nilai yang tidak signifikan atau tidak sesuai dengan ketentuan. Hubungan customer satisfaction berpengaruh positif tetapi tidak signi- 
fikan terhadap behavioural loyalty. H4 memiliki nilai standard estimate 0,191 dan C.R. 1,513. Pembahasan hubungan setiap hipotesis akan dijelaskan pada bab berikutnya untuk mengetahui hubungan yang ada berdasarkan jurnal pendukung. Hasil pengujian hipotesis dari konsumen OVO dapat dilihat pada Tabel 4 berikut.

Tabel 4 Uji Hipotesis

\begin{tabular}{|c|c|c|c|c|c|}
\hline \multicolumn{2}{|c|}{ Hipotesis } & \multirow{2}{*}{$\begin{array}{c}\begin{array}{c}\text { Standardised } \\
\text { Estimate }\end{array} \\
0.705\end{array}$} & \multirow{2}{*}{$\begin{array}{l}\text { C.R. } \\
7,369\end{array}$} & \multirow{2}{*}{$\begin{array}{c}\text { P-Value } \\
\ldots\end{array}$} & \multirow{2}{*}{$\begin{array}{c}\text { Keterangan } \\
\text { Hipotesis } \\
\text { Terdukung }\end{array}$} \\
\hline $\mathrm{H} 1(+)$ & $\mathrm{SMM} \rightarrow$ SAT & & & & \\
\hline $\mathrm{H} 2(+)$ & $5 \mathrm{MM} \rightarrow \mathrm{PVL}$ & 0,672 & 6,287 & $\cdots$ & $\begin{array}{l}\text { Hapotesis } \\
\text { Terdukung }\end{array}$ \\
\hline $\mathrm{H} 3(+)$ & SAT $\rightarrow$ ATT & 0,582 & 4,336 & $\cdots$ & $\begin{array}{l}\text { Hipotesis } \\
\text { Terdukung }\end{array}$ \\
\hline $\mathrm{H} 4\left(^{+}\right)$ & $\mathrm{SAT} \rightarrow \mathrm{BVL}$ & 0,191 & 1,513 & 0,130 & $\begin{array}{c}\text { Hipotesis } \\
\text { Tidak Terdukung }\end{array}$ \\
\hline $\mathrm{H} 5(+)$ & PVL $\rightarrow$ ATT & 0,309 & 2,799 & $0,005(" *)$ & $\begin{array}{l}\text { Hipotesis } \\
\text { Terdukung }\end{array}$ \\
\hline $\mathrm{H} 6(+)$ & PVL $\rightarrow$ BVL & 0,270 & 2,763 & $0,006(" 7)$ & $\begin{array}{l}\text { Hipotesis } \\
\text { Terdukung }\end{array}$ \\
\hline $\mathrm{H} \nabla(+)$ & ATT $\rightarrow$ BVL & 0,534 & 3,707 & $\cdots$ & $\begin{array}{l}\text { Hipotesis } \\
\text { Terdukung. }\end{array}$ \\
\hline
\end{tabular}

C.R. $=$ Critical Ratio; ${ }^{* *}<0,001 ; * *<0,05$

Pada penelitian kali ini semua nilai dari standard estimate atau SE dapat diterima karena memiliki arah hubungan sesuai yaitu positif. $\mathrm{H} 1$ mendapatkan nilai 0,705 . H2 mendapatkan nilai $+0,672$. H3 mendapatkan nilai 0,582. H4 mendapatkan nilai 0,191 . H5 mendapatkan nilai 0,309. H6 mendapatkan nilai 0,270. Sedangkan $\mathrm{H} 7$ mendapatkan nilai $+0,534$. Seluruh hasil standard estimate mendapat nilai yang memuaskan sesuai dengan hipotesis yang arahnya adalah positif. Pada penelitian kali ini tidak dijumpai hubungan yang negatif. Model dan nilai hasil dari standard estimate dapat dilihat pada gambar berikut.

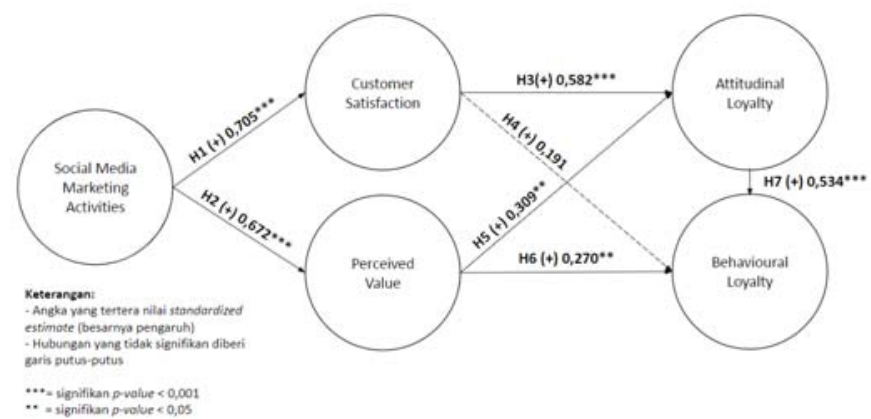

Gambar 1 Model Hasil Nilai Standard Estimate
Hipotesis 1 atau $\mathrm{H} 1$ dapat diterima atau terdukung. Penelitian terdahulu juga menjelaskan bahwa aktivitas pemasaran menggunakan media sosial memiliki peranan yang penting untuk membangun kepuasan dari pelanggan (Clark dan Melancon, 2013; Sano, 2014). Peningkatan aktivitas pemasaran dari OVO melalui media sosial akan dapat meningkatkan kepuasan pelanggan OVO agar puas menggunakan OVO sebagai dompet digital mereka. Menurut Khan (2019) juga menjelaskan bahwa aktivitas melalui media sosial merupakan alat pemasaran yang ampuh dan memiliki banyak pengguna. Menurut penelitian dari Hanaysha (2017) juga mengungkap bahwa pengolahan media sosial yang baik untuk pemasaran dapat meningkatkan kepuasan pelanggan secara signifikan. Strategi penggunaan media sosial untuk kegiatan pemasaran untuk meningkatkan perhatian dan kepuasan konsumen terhadap perusahaan dompet digital sudah digunakan (www.blog.nolimit.id diunduh pada 7 November 2020).

Hipotesis 2 atau $\mathrm{H} 2$ dapat diterima atau terdukung. Hasil penelitian Chen dan Lin (2019) mengungkapkan semakin tinggi penggunaan media sosial sebagai alat untuk pemasaran akan meningkatkan juga perceived value dari perusahaan tersebut. Semakin tinggi perusahaan OVO untuk menggunakan media sosial dari Instagram untuk melakukan kegiatan pemasaran akan semakin tinggi perceived value dari perusahaan OVO. Masyarakat atau pengguna OVO dapat menilai OVO memiliki nilai-nilai yang positif. Nilai positif yang akan terlihat seperti estetika dari Instagram OVO, kenyamanan pengguna OVO, transaksi menggunakan OVO akan menghemat waktu, dan terakhir kemampuan OVO untuk selalu memberikan pelayanan kepada pengguna. Hal ini juga dapat dilihat bahwa media sosial Instagram banyak dipakai oleh per- 
usahaan untuk branding perusahaan dan digunakan sebagai kegiatan pemasaran untuk mendorong laju performa perusahaan. Media sosial di Instagram juga digunakan untuk meningkatkan nilai-nilai perusahaan (www.tirto.id diunduh pada 28 Oktober 2020).

Hipotesis 3 atau $\mathrm{H} 3$ dapat diterima atau terdukung. Menurut Chen (2019) juga mengungkapkan bahwa konsumen yang puas terhadap suatu produk atau jasa maka bisa memengaruhi orang atau konsumen tersebut untuk menjadi pelanggan yang loyal terhadap perusahaan tersebut. Pernyataan tersebut juga didukung oleh penelitian dari Lee et al. (2018) bahwa semakin meningkatnya rasa kepuasan konsumen terhadap barang jasa akan meningkatkan attitudinal loyalty terhadap perusahaan tersebut. Menurut penelitian dari Akamavi et al. (2015), customer satisfaction atau kepuasan pelanggan memiliki pengaruh yang kuat terhadap loyalitas secara keseluruhan. Penelitian Akamavi et al. (2015) dan penelitian Lee et al. (2018) berhubungan dengan industri pesawat terbang. Ternyata hal ini juga sesuai dengan industri dompet digital bahwa ada pengaruh yang kuat antara kepuasan pelanggan dengan loyalitas. Tetapi jika dilihat dari hasil kepuasan pelanggan OVO hanya berpengaruh signifikan terhadap attitudinal loyalty saja, sedangkan untuk behavioural loyalty tidak signifikan. Hal ini akan dibahas pada subbab selanjutnya. Konsumen dompet digital yang puas akan cenderung menjadi loyal (www.arenalte. com diunduh pada 7 November 2020).

Hipotesis 4 atau $\mathrm{H} 4$ tidak dapat diterima atau tidak dapat terdukung. Penelitian dari Shahin dan Rahim (2014) mengungkapkan bahwa kepuasan konsumen seharusnya memiliki hubungan yang positif dan signifikan kepada attitudinal loyalty dan behavioural loyalty. Penelitian dari Tsai dan Huang (2017) juga mengungkapkan bahwa pelanggan yang puas akan melakukan pembelian ulang terus menerus terhadap produk atau jasa. Ternyata dalam penelitian kali ini tidak dapat terdukung. Hasil penelitian ini ternyata sesuai dengan penelitian dari Lee et al. (2018) yang mengungkapkan bahwa kepuasan dari pelanggan berpengaruh positif terhadap loyalitas keseluruhan seperti attitudinal loyalty dan behavioural loyalty, tetapi pengaruh kepuasan pelanggan lebih signifikan terhadap attitudinal loyalty. Pada bagian behavioural loyalty tidak terlalu signifikan. Hal ini ditunjukkan dari hasil penelitian konsumen OVO hubungan customer satisfaction dan behavioural loyalty memiliki nilai C.R. dan $p$-value yang tidak dapat diterima atau tidak terdukung.

Penelitian terdahulu dari Taylor dan Baker (1994) mengungkapkan bahwa konsumen yang puas ketika ingin membeli ulang barang tersebut akan lebih signifikan melalui efek attitudinal loyalty. Fenomena ini terjadi pada konsumen OVO. Jika konsumen OVO yang relatif anak muda ketika merasa puas terhadap performa OVO mereka cenderung untuk menjadi konsumen yang loyal baru mereka akan melakukan transaksi ulang dan menggunakan OVO sebagai dompet digital utamanya. Hal ini terjadi karena OVO membuat akomodasi loyalitas dari pengguna (www.dailysocial.id diunduh 28 Oktober 2020). Ada program khusus loyalitas dari OVO yaitu OVO Poin yang bisa dikumpulkan untuk berbelanja kembali sehingga konsumen yang puas akan menjadi loyal dengan menggunakan program loyalitas dan menggunakan OVO lagi untuk melakukan transaksi ulang.

Hipotesis 5 atau H5 dapat diterima atau terdukung. Menurut Llach et al. (2013) mengungkapkan bahwa perceived value memiliki hubungan positif dan signifikan terhadap loyalitas dari konsumen. Hal ini juga diperkuat dengan 
penelitian dari El-Adly dan Eid (2016) yang mengungkapkan bahwa perceived value yang menurun dapat menyebabkan penurunan terhadap loyalitas konsumen. Fenomena ini juga terjadi pada penelitian kali ini. Konsumen OVO menilai bahwa nilai-nilai yang dimiliki perusahaan OVO sangat baik. Nilai tersebut adalah tampilan dan konten Instagram OVO yang menarik secara estetika. Konsumen OVO juga sangat nyaman mencari informasi di Instagram OVO dan menggunakan dompet digital OVO. Konsumen juga sangat setuju bahwa Instagram OVO dan transaksi menggunakan OVO dapat menghemat waktu. Terakhir para konsumen OVO sangat puas dengan pelayanan yang diberikan OVO. Nilai-nilai baik yang dimiliki oleh OVO ini berpengaruh besar terhadap attitudinal loyalty yang dimiliki oleh OVO.

Hipotesis 6 atau H6 dapat diterima atau terdukung. Penelitian terdahulu dari Duman dan Mattila (2005) juga mengungkapkan bahwa peningkatan nilai perusahaan atau perceived value dari perusahaan semakin meningkat dapat memengaruhi keputusan orang untuk menggunakan produk atau jasa tersebut. Hal ini juga didukung oleh penelitian Kim dan Ok (2009) yang mengatakan bahwa ada hubungan yang sangat kuat antara nilai yang dimiliki perusahaan untuk menggunakan ulang produk tersebut. Kemudian penelitian dari Chua, Lee, dan Han (2017) lebih mempertegas lagi bahwa perceived value atau nilai dari perusahaan tersebut memiliki hubungan yang positif dan signifikan terhadap behavioural loyalty dari konsumen OVO.

Jika dilihat dari hasil penelitian ini sangat berbanding terbalik dengan customer satisfaction. Pembahasan sebelumnya telah menyatakan bahwa customer satisfaction memiliki hubungan positif terhadap behavioural loyalty tetapi tidak signifikan. Namun demikian, pada variabel per- ceived value dapat dilihat memiliki hubungan positif dan signifikan terhadap behavioural loyalty. Hal ini menunjukkan bahwa penggunaan media sosial sebagai alat pemasaran kemudian menumbuhkan kepuasan pelanggan tidak akan signifikan meningkatkan transaksi ulang dari OVO. Peningkatan nilai atau perceived value yang dimiliki oleh perusahaan dapat memberikan dampak positif dan peningkatan yang signifikan terhadap behavioural loyalty. Hal ini sesuai dengan fenomena yang terjadi pada masyarakat, saat ini dompet digital OVO dapat bertumbuh pesat karena konsumen dari OVO sudah paham dengan manfaat dan nilai-nilai baik yang dimiliki oleh perusahaan OVO bukan karena promopromo lagi (www.inet.detik.com diunduh 28 Oktober 2020). Konsumen saat ini lebih memedulikan dalam sektor kenyamanan dan keamanan yang dimiliki oleh perusahaan dompet digital. Sehingga mereka lebih mudah untuk melakukan transaksi ulang.

Hipotesis 7 atau $\mathrm{H} 7$ dapat diterima atau terdukung. Penelitian terdahulu mengungkapkan bahwa konsumen akan melakukan transaksi ulang barang dan jasa dipengaruhi oleh efek attitudinal loyalty (Taylor dan Baker, 1994). Penelitian ini juga diperkuat dengan hasil penelitian Lee et al. (2018) bahwa attitudinal loyalty memiliki pengaruh positif dan signifikan terhadap behavioural loyalty. Penelitian dari Aziz (2018) juga mengungkapkan bahwa emosi positif dari seseorang terkait loyalitas dapat memengaruhi keputusan seseorang untuk memiliki hubungan loyal dan menggunakan produk atau jasa tersebut. Penelitian terbaru dari Saini dan Singh (2020) juga mengungkapkan bahwa attitudinal loyalty memiliki hubungan yang kuat dan positif terhadap behavioural loyalty. Hal ini sesuai dengan penelitian pada konsumen OVO. Perasaan loyalitas dan mau merekomendasikan 
OVO pada keluarga, teman maupun orang terdekat dapat meningkatkan keinginan menggunakan OVO lagi dan menjadikan OVO sebagai dompet digital utama.

\section{KONKLUSI}

Hasil dari penelitian menunjukkan ada pengaruh yang positif dan signifikan antara social media marketing activities dari Instagram OVO dengan customer satisfaction dari pelanggan OVO. Adanya pengaruh yang positif dan signifikan antara social media marketing activities dari Instagram OVO dengan perceived value dari pelanggan OVO. Adanya pengaruh yang positif dan signifikan antara customer satisfaction dengan attitudinal loyalty dari pelanggan OVO. Adanya pengaruh yang positif dan tidak signifikan antara customer satisfaction dengan behavioural loyalty dari pelanggan OVO. Sehingga $\mathrm{H} 4$ tidak terdukung. Adanya pengaruh yang positif dan signifikan antara perceived value dengan attitudinal loyalty dari pelanggan OVO. Adanya pengaruh yang positif dan signifikan antara perceived value dengan behavioural loyalty dari pelanggan OVO. Adanya pengaruh yang positif dan signifikan antara attitudinal loyalty dengan behavioural loyalty dari pelanggan OVO sehingga $\mathrm{H} 7$ terdukung.

Penggunaan media sosial dalam kegiatan pemasaran sangat berpengaruh cukup besar pada kepuasan pelanggan, hanya berbeda tipis dengan perceived value. Akan tetapi, jika dilihat hubungan berikutnya, nilai perceived value sangat kuat terhadap attitudinal loyalty dan behavioural loyalty. Dengan demikian, peneliti merekomendasikan ke OVO untuk menggunakan media sosial Instagram OVO untuk mempertahankan estetika dari tampilan Instagram OVO kemudian mengikuti zaman agar sesuai dengan tren tampilan
Instagram yang sesuai. Selain itu, OVO juga bisa menggunakan media sosial Instagram OVO untuk menampilkan perceived value atau nilainilai baik yang dimiliki OVO sehingga dapat meningkatkan tidak hanya attitudinal loyalty tetapi berdampak langsung terhadap behavioural loyalty yaitu konsumen OVO akan menggunakan ulang dan menjadi OVO sebagai dompet digital utama.

Jika dilihat dari data situs iPrice, OVO saat ini mendapatkan peringkat kedua sebagai pengguna aktif dari perusahaan. Peringkat pertama adalah perusahaan Go-Pay. Sampai saat ini pun di tahun 2020, Go-Pay mampu untuk menjadi dompet digital dengan peringkat pertama (www.inet.detik.com diunduh 28 Oktober 2020). Go-Pay banyak digunakan sekitar 58\%, OVO 29\%, DANA 9\%, dan LinkAja sekitar 4\%. Menurut situs tersebut juga mengungkapkan bahwa Go-Pay bisa mendapatkan peringkat teratas bukan semata-mata karena promo yang diberikan oleh Go-Pay atau istilahnya bakar duit perusahaan tetapi masyarakat percaya terhadap keamanan dan kenyamanan yang dimiliki oleh GoPay sehingga masyarakat lebih puas untuk menggunakan OVO dari pada Go-Pay. Hal lain yang membuat Go-Pay menjadi lebih unggul karena mampu memberikan cash back yang lebih besar dibandingkan dengan OVO (www.tirto.id diunduh 7 Desember 2020). Selain itu Go-Pay juga lebih unggul ketika melakukan top-up bisa melalui mitra Go-Jek sehingga tidak perlu membayar biaya admin tambahan (www.cekaja.com diunduh 7 Desember 2020).

Rekomendasi yang bisa diberikan OVO agar lebih unggul dari pesaingnya Go-Pay adalah meningkatkan kepuasan dari pelanggan untuk menaikkan penggunaan aktif. Cara meningkatkannya dengan memberi keamanan dan kenyamanan lebih. Mampu memberikan cash back 
atau promo yang lebih menjanjikan dibandingkan dengan pesaingnya. Memperkecil biaya admin agar bisa lebih menarik minat pelanggan. Selain itu, media sosial OVO dapat digunakan juga dengan menambah promo-promo yang menarik dan tentu menguntungkan pihak konsumen agar mereka mau menggunakan ulang OVO. Perusahaan ini harus terus dapat meningkatkan kepuasan pelanggan agar mau menggunakan dompet digital tersebut.

Penelitian ini hanya untuk melihat penggunaan media sosial sebagai aktivitas pemasaran dari dompet digital OVO. Pada penelitian selanjutnya bisa membandingkan juga aktivitas pemasaran melalui media sosial dari dompet digital yang lain seperti Go-Pay, DANA, dan LinkAja. Selain itu, media sosial yang digunakan hanya Instagram padahal OVO selain Instagram juga memiliki Facebook dan Twitter juga. Penelitian ini juga terbatas untuk dompet digital di Indonesia. Selanjutnya penelitian ini bisa menggunakan dompet digital di luar Indonesia. Penelitian ini juga terbatas menyebarkan kuesioner hanya pada orang terdekat saja sehingga perlu diperluas penyebaran kuesioner.

Penelitian ini juga terbatas hanya menggunakan satu variabel yang digabungkan menjadi perceived value. Penelitian selanjutnya bisa membagi perceived value menjadi aesthetic, playfulness, consumer return on investment (CROI), dan service excellence untuk mengetahui variabel perceived value mana yang lebih berdampak terhadap hubungan social media marketing activities terhadap loyalitas dari konsumen. Penelitian selanjutnya juga bisa menguji variabel mediasi agar lebih mengetahui nilai kekuatan hubungan antara variabel.

\section{DAFTAR PUSTAKA}

Akamavi, R.K., Mohamed, E., Pellmann, K., \& $\mathrm{Xu}, \mathrm{Y}$. 2015. Key determinants of passenger loyalty in the low-cost airline business. Tourism Management, 46, pp. 528545.

Arena LTE. 2020. Ini Dompet Digital Sering Digunakan Konsumen Indonesia Bertransaksi Di Pandemi. Dikutip 7 November 2020, https://arenalte.com/berita/fintech/ ini-dompet-digital-sering-digunakan-konsumen-indonesia-bertransaksi-di-pandemi/

Bandyopadhyay, S. \& Martell, M. 2007. Does attitudinal loyalty influence behavioral loyalty? A theoretical and empirical study. Journal of Retailing and Consumer Services, 14(1), pp.35-44.

Belch, G.E. \& Belch, M.A. 2004. Advertising and promotion: An integrated marketing communications perspective 6th. New York: McGraw-Hil 1.

Cekaja.com. 2019. Perbandingan Gopay dan OVO. Siapakah yang Terbaik ? Dikutip dari 7 Desember 2020, https://www.cekaja. com/info/perbandingan-gopay-dan-ovoyang-perlu-diketahui-siapakah-yang-terbaik.

Chen, S.C. \& Lin, C.P. 2019. Understanding the effect of social media marketing activities: The mediation of social identification, perceived value, and satisfaction. Technological Forecasting and Social Change, 140, pp.22-32.

Chua, B.L., Lee, S. \& Han, H. 2017. Consequences of cruise line involvement: A comparison of first-time and repeat passengers. International Journal of Contemporary Hospitality Management. 
Daily Social. 2017. OVO Mantapkan Diri Jadi Platform Akomodasi Loyalitas Pengguna. Dikutip 28 Oktober 2020, https://dailysocial.id/post/ovo-mantapkan-diri-jadi-platform-akomodasi-loyalitas-pengguna.

Detik Net. 2020. Hasil Riset: Go-Pay Jadi Dompet Digital Favorit meski tanpa Promo. Dikutip 28 Oktober 2020, https://inet. detik.com/cyberlife/d-4906576/hasil-risetgopay-jadi-dompet-digital-favorit-meskitanpa-promo.

Dunman, T. \& Mattila, A.S., 2005. The role of affective factors on perceived cruise vacation value. Tourism Management, 26(3), pp.311-323.

El-Adly, M.I. \& Eid, R., 2016. An empirical study of the relationship between shopping environment, customer perceived value, satisfaction, and loyalty in the UAE malls context. Journal of Retailing and Consumer Services, 31, pp.217-227.

Khan, M.M. 2019. The Impact of Perceived Social Media Marketing Activities: An Empirical Study in Saudi Context. International Journal of Marketing Studies, 11(1), p.134.

Kim, W. \& Ok, C. 2009. The effects of relational benefits on customers' perception of favorable inequity, affective commitment, and repurchase intention in fullservice restaurants. Journal of Hospitality \& Tourism Research, 33(2), pp.227244.

Kompas. 2019. Tumbuh Pesat, Ini Tantangan Ecommerce untuk Raih Loyalitas Konsumen. Dikutip 3 November 2019, https:// money.kompas.com/read/2019/03/26/ 192803026/tumbuh-pesat-ini-tantangan-ecommerce-untuk-raih-loyalitas-konsumen
Kotler, P., Keller, K.L., Ang, S.H., Tan, C.T., \& Leong, S.M. 2018. Marketing Management: An Asian Perspective (7 ${ }^{\text {th }}$ ed.). England: Pearson.

Lee, C.K., Ng, K.K.H., Chan, H.K., Choy, K.L., Tai, W.C., \& Choi, L.S. 2018. A multi-group analysis of social media engagement and loyalty constructs between full-service and low-cost carriers in Hong Kong. Journal of Air Transport Management, 73, pp.46-57.

Llach, J., Marimon Viadiu, F., Alonso-Almeida, M.D.M. \& Bernardo, M., 2013. Determinants of on-line booking loyalties for airline ticket purchasing. Tourism Management.

Macy, B. 2011. The power of real-time social media marketing: How to attract and retain customers and grow the bottom line in the globally connected world.

Nolimit. 2020. Mengintip Strategi Konten EWallet Indonesia. Dikutip 7 November 2020, https://blog.nolimit.id/2019/11/26/ mengintip-strategi-konten-e-wallet-indonesia/.

Saini, S. \& Singh, J., 2020. A Link Between Attitudinal and Behavioral Loyalty of Service Customers. Business Perspectives and Research, 8(2), pp.205-215.

Sano, K. 2014. Do social media marketing activities enhance customer satisfaction, promote positive WOM and affect behavior intention? an investigation into the effects of social media on the tourism industry. $T \times_{-}>y F U f[, 66(3)$, pp.491-515.

Santoso, A.S. \& Erdaka, A., 2015. Customer loyalty in collaborative consumption model: Empirical study of CRM for product-service system-based e-commerce in 
Indonesia. Procedia computer science, 72 , pp.543-551.

Sekaran, U. \& Bougie, R., 2016. Research Methods for Business 7 th ed. John Wiley.

Sharifi, S.S. \& Esfidani, M.R. 2014. The impacts of relationship marketing on cognitive dissonance, satisfaction, and loyalty. International Journal of Retail \& Distribution Management.

Taylor, S.A. \& Baker, T.L., 1994. An assessment of the relationship between service quality and customer satisfaction in the formation of consumers' purchase intentions. Journal of retailing, 70(2), pp.163-178.
Tirto.id. 2019. Go-Pay vs OVO: Mana yang Kini Berhasil Merebut Hati Pengguna? Dikutip dari 7 Desember 2020, https:// tirto.id/gopay-vs-ovo-mana-yang-kiniberhasil-merebut-hati-pengguna-ecHz

Tirto.id. 2020. Tips Memanfaatkan Media Sosial untuk Branding Bisnis Saat Pandemi. Dikutip dari 28 Oktober 2020, https://tirto.id/ tips-memanfaatkan-media-sosial-untukbranding-bisnis-saat-pandemi-fKxX/

Tjepkema, L. 2019. 5 Big Social Media Predictions for 2019 | Emarsys. Retrieved 3 November 2019, from https://www.emarsys.com/resources/blog/top-5-social-mediapredictions-2019. 